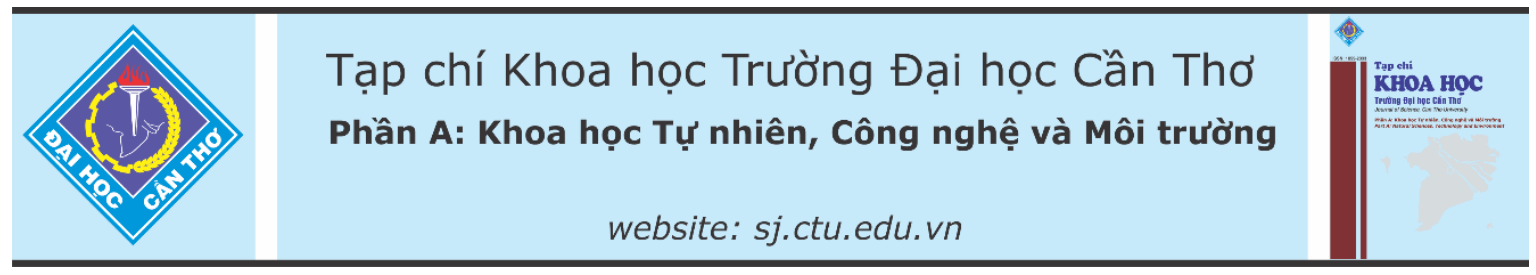

DOI:10.22144/ctu.jvn.2021.083

\title{
ĐÁNH GIÁ HIỆN TRẠNG VÀ CÔNG TÁC QUẢN LÝ RÁC THẢI ĐIỆN TỬ GIA DỤNG TẠI THẦNH PHỐ CẦN THO
}

\author{
Nguyễn Thanh Giao*, Lâm Thị Kiều Trinh và La Nguyễn Khiết Linh \\ Bộ môn Quản lý Môi truờng, Khoa Môi truờng và Tài nguyên Thiên nhiên, Truờng Đại học Cần Tho \\ *Ngưòi chịu trách nhiệm về bài viết: (email: ntgiao@ctu.edu.vn)
}

\section{Thông tin chung:}

Ngày nhận bài: $31 / 12 / 2020$

Ngày nhận bài sủa: 19/04/2021

Ngày duyệt đăng: 25/06/2021

\section{Title:}

Assessment of the current status and management of household electronic wastes in Can Tho city

\section{Tù khóa:}

Công tác quản lý, rác thải điện tử gia dụng, thành phố Cần Tho, thải bỏ, thu gom

\section{Keywords:}

Can Tho city, collection, disposal, household electronic waste, management

\begin{abstract}
This study was implemented to assess the current status of generation, collection, recycling and management of household electronic waste (e-waste) in several wards in Can Tho city including An Hoa (Ninh Kieu district), Ba Lang (Cai Rang district), Long Tuyen (Binh Thuy district), and Tan Loc (Thot Not district). The household survey method was applied by randomly interviewing 120 households and 16 e-waste collection and treatment facilities in the area in August 2020. The results of the current status of using household electronic devices based on the number of devices used per household were arranged in the following order: mobile phone and electric fan $>$ television $>$ refrigerator $>$ air conditioner $>$ washing machine $>$ computer with the average mean rates of $3.58,1.48,1.01,0.78,0.72$, and 0.50 pcs/household, respectively. The average life expectancy of the devices was relatively high, ranging from 6 to 12 years (except for mobile phones). According to the estimated results, telephones and electric fans are the two devices used and may have the highest rate of waste generation in the city. Safe collection, treatment and disposal programs have not been implemented in the study area, but mainly selling scrap and repairing. The survey results also showed that there was a limitation in awareness of respondents about the impacts of e-waste. Therefore, further studies on the causes of these limitations are needed in the future.
\end{abstract}

\section{TÓM TÁ̀T}

Nghiên cưu thực hiện nhằm đánh giá hiện trạng phát sinh, hoạt động thu gom, tái chế và công tác quản lý rác thải điện tử gia dưng tại các phuoòng An Hòa (quận Ninh Kiều), Ba Láng (quận Cái Răng), Long Tuyền (quận Bình Thưy) và Tân Lộc (quận Thốt Nốt) thuộc thành phố Cần Tho: Phuong pháp điều tra hộ dân đã được áp dụng bằng cách phỏng vấn ngẫu nhiên 120 hộ dân và 16 cơ sở thu mua, xử lý rác thải điện tủ gia dụng vào tháng 8/2020. Kết quả ghi nhận được hiện trạng sủ dụng các thiết bị điện tư gia dụng dựa vào số luợng thiết bị sư dụng/hộ được sắp xếp theo thư tụ sau: diện thoại di động và quat điện $>$ ti vi $>$ tủ lạnh $>$ máy điè̀u hòa $>$ máy giắt $>$ máy vi tính, với tỷ lẹ trung binh làn luoơt là 3,58; 1,48; 1,01; 0,78; 0,72 và 0,50 chiếc/hộ. Tuổi tho trung bình của các thiết bị tuoong đối cao dao động tù $6-12$ năm (ngoại trù̀ điện thoại di động). Theo kết quả uớc tính, điện thoại và quạt điện là hai thiết bi được sủ dụng và có thể có tỷ lẹ phát sinh rác thải nhiều nhất trên địa bàn thành phố. Tại khu vưc nghiên cứu chưa triển khai các chưong trình thu gom và xử lý an toàn, chủ yếu chỉ bán phế liệu và sứa chữa. Kết quả điều tra cũng cho thấy hạn chếtrong nhận thức của đáp viên về các tác động của rác thải điện tử; do đó, những nghiên cứu sâu hơn về nguyên nhân của nhũng hạn chế này là cần thiết trong tương lai. 


\section{GIỚI THIẸU}

Rác thải điện tử (e-waste) là các thiết bị điện, điện tử bị thải bỏ do đã đạt đến tuổi thọ thiết bị hoặc do không còn đáp ứng được các yêu cầu của người sở hữu (Đặng Thị Hường, 2013). Trong những năm gần đây, sự ra đời của các thiết bị điện tử mới đã thúc đẩy lượng thiết bị điện tử thải bỏ ngày càng tăng và đây được xác định là một trong những dòng rác thải đô thị phát triển nhanh nhất (Ohajinwa et al., 2017; Zeng et al., 2017). Tại Việt Nam, rác thải điện tử nói chung và rác thải điện tử gia dụng nói riêng thường được thu gom bởi những người thu mua phế liệu tự do và việc tái chế mới chỉ dừng lại ở khâu tháo dỡ và phân tách để thu kim loại (Nguyễn Thu Hiền \& Trần Phương Thảo, 2019; Nguyễn Thị Thoa và ctv., 2020). Phương pháp phân tách thủ công tại các làng nghề này chỉ có thể thu hồi được một số kim loại cơ bản như sắt, đồng, nhôm,... với hiệu suất thấp và tiềm ẩn nhiều rủi ro gây ô nhiễm môi trường không khí, đất và nước xung quanh các khu tái chế (Perkins et al., 2014; Hai et al., 2015; Zeng et al., 2017; Nguyễn Thu Hiền \& Trần Phương Thảo, 2019; Nguyễn Thị Thoa và ctv., 2020). Các mẫu đất tại các làng nghề tái chế rác thải điện tử ghi nhận nồng độ kim loại nặng cao hơn các mẫu đối chiếu ở những vùng lân cận (Someya et al., 2016; Hien et al., 2020). Bên cạnh đó, có $90 \%$ trong tổng số 20 mẫu nước lấy từ các giếng khoan xung quanh khu vực tái chế có hàm lượng $\mathrm{Cd}, \mathrm{Cr}, \mathrm{Cu}, \mathrm{Ni}, \mathrm{Mn}$ cao hơn tiêu chuẩn cho phép của nước ngầm; $75 \%$ số giếng bị ô nhiễm Co và $50 \%$ các giếng có dấu hiệu ô nhiễm $\mathrm{Pb}$ (Tạ Thị Thảo và ctv., 2014). Hơn nữa, việc tiếp xúc trực tiếp với rác thải điện tử từ quá trình thu gom và tái chế đã làm tích lũy hàm lượng cao các kim loại $\mathrm{As}, \mathrm{Zn}, \mathrm{Cu}, \mathrm{Cr}$, Co trong tóc và móng tay của những người cao tuổi tại khu vực tái chế (Tạ Thị Thảo và ctv., 2014). Ngoài ra, chúng còn gây ra những ảnh hưởng về chức năng phổi, tuyến giáp, thần kinh, rối loạn nội tiết, thậm chí có thể gây ung thư (Perkins et al., 2014). Đặc biệt, nhận thức của người dân về rác thải điện tử tại các khu vực nghiên cứu là chưa cao (Nguyễn Thu Hiền \& Trần Phương Thảo, 2019; Olowofoyeku, 2020) thậm chí phần lớn người được phỏng vấn chưa bao giờ nghe đến thuật ngữ "e-waste". Từ các tác động trên có thể thấy việc tiến hành nghiên cứu đánh giá hiện trạng sử dụng, phát sinh, công tác quản lý và nhận thức của người dân về các ảnh hưởng của rác thải điện tử đến môi trường và sức khỏe cộng đồng là cần thiết, đặc biệt là tại các tỉnh thành phía Nam. Vì hầu hết các nghiên cứu liên quan đến rác thải điện tử ở nước ta chủ yếu được thực hiện tại các tỉnh miền Bắc, nơi tập trung nhiều làng nghề tái chế rác thải điện tử. Trên cơ sở đó, nghiên cứu này được thực hiện nhằm thống kê hiện trạng phát sinh; đánh giá hoạt động thu gom, tái chế; công tác quản lý rác thải điện tử gia dụng và nâng cao nhận thức cho người dân tại thành phố Cần Tho.

\section{PHƯƠNG PHÁP NGHIÊN CÚU}

\subsection{Thời gian và địa điểm nghiên cứu}

Nghiên cứu được thực hiện vào tháng 8/2020 bằng cách khảo sát và điều tra phỏng vấn tại 4 phường thuộc các quận Ninh Kiều, Cái Răng, Bình Thủy và Thốt Nốt của thành phố Cần Thơ (TPCT). Trong mỗi quận, nghiên cứu tiến hành chọn ngẫu nhiên 01 phường để thực hiện phỏng vấn do tất cả các phường thuộc những quận này đều có $100 \%$ dân số được phân theo thành thị.

\subsection{Thu thập số liệu}

Thu thập, kế thừa những số liệu và thông tin thứ cấp từ các bài báo liên quan đến rác thải điện tử trong và ngoài nước và các văn bản pháp lý quy định về rác thải điện tử.

Khảo sát thực địa và thu thập thông tin bằng cách phỏng vấn trực tiếp hoặc phát phiếu phỏng vấn. Phiếu phỏng vấn được thiết kế thành hai loại: (1) Phiếu thu thập thông tin về hiện trạng sử dụng và thải bỏ các thiết bị điện, điện tử gia dụng và công tác quản lý rác thải điện tử gia dụng tại địa phương; (2) Phiếu thu thập thông tin về số lượng và cách thức thu gom, tái chế các thiết bị điện tử gia dụng đã qua sử dụng, cùng các lợi ích và tác hại của rác thải điện tử. Nghiên cứu thực hiện khảo sát hiện trạng sử dụng của 7 loại thiết bị điện tử gia dụng phổ biến, bao gồm điện thoại di động (ĐTDĐ), quạt điện, ti vi, tủ lạnh, máy giặt, máy điều hòa và máy vi tính. Để có thể đánh giá và so sánh số liệu giữa các địa điểm, số lượng phiếu phỏng vấn và loại phiếu phỏng vấn cho mồi đối tượng phỏng vấn tại mỗi địa điểm nghiên cứu là bằng nhau (Bảng 1$)$.

\section{Bảng 1. Loại phiếu và số lượng phiếu phỏng vấn cho mỗi đối tượng tại từng địa điểm}

\begin{tabular}{|c|c|c|c|}
\hline \multirow{2}{*}{ Đối tượng phỏng vấn } & \multirow{2}{*}{$\begin{array}{l}\text { Loại phiếu } \\
\text { phỏng vấn }\end{array}$} & \multicolumn{2}{|c|}{ Số lượng phiếu phỏng vấn } \\
\hline & & Tại mỗi địa điểm & Tổng cộng \\
\hline Người dân và cán bộ địa phương & (1) & $\begin{array}{l}30 \text { phiếu ( } 29 \text { người dân và } 01 \text { cán bộ } \\
\text { địa phương) }\end{array}$ & 120 phiếu \\
\hline Người thu gom, vận chuyển và xử lý & (2) & 04 phiếu & 16 PHIẾU \\
\hline
\end{tabular}




\subsection{Phương pháp xử lý số liệu}

Các số liệu về hiện trạng sử dụng, thải bỏ và công tác quản lý rác thải điện tử gia dụng được xử lý bằng phần mềm Microsoft Excel 2019 để lập bảng thống kê mô tả và vẽ biểu đồ.

Bên cạnh đó, nghiên cứu tiến hành ước tính lượng rác thải điện tử gia dụng từ 07 loại thiết bị được khảo sát phát sinh trên địa bàn thành phố Cần Thơ bằng phương pháp gần đúng (Bùi Duy Cam và ctv., 2013) với giả định cho thị trường bão hòa. Theo đó, lượng rác thải điện tử gia dụng phát sinh sẽ được tính bằng với lượng thiết bị điện tử gia dụng đang sử dụng. Tổng lượng thiết bị điện tử gia dụng (7 loại khảo sát) đang sử dụng tại $\mathrm{TPCT}$ được tính bằng công thức sau:

$$
\mathrm{E}=\mathrm{A} \times \mathrm{X}
$$

Trong đó:

E là tổng lượng thiết bị điện tử gia dụng đang sử dụng tại TPCT (chiếc);

A là tỷ lệ sử dụng của từng loại thiết bị (chiếc/người), được tính bằng cách lấy tổng số lượng từng loại thiết bị đang được sử dụng chia cho tổng số nhân khẩu trong 120 hộ gia đình được phỏng vấn;

X là dân số của toàn TPCT năm 2019 (người).

\section{KẾT QUẢ VÀ THẢO LUẬN}

\subsection{Hiện trạng sử dụng và phát sinh các thiết bị điện tử gia dụng thải bỏ}

\subsubsection{Hiện trạng sủ dụng các thiết bị điện tủ gia dung}

Kết quả khảo sát hiện trạng sử dụng của 7 loại thiết bị điện tử tại các địa điểm nghiên cứu cho thấy các hộ dân được phỏng vấn tại phường An Hòa có tổng số thiết bị được sử dụng nhiều nhất với 403 thiết bị; cao gấp 1,3 lần so với các hộ dân được phỏng vấn tại phường Ba Láng (chỉ có 309 thiết bị) và phường Long Tuyền (311 thiết bị) (Bảng 2). Tuy nhiên, tổng số thiết bị đang được sử dụng giữa các hộ dân được phỏng vấn tại phường An Hòa và phường Tân Lộc không có sự chênh lệch. Nguyên nhân dẫn đến sự khác biệt về số lượng thiết bị đang được sử dụng giữa các địa điểm nghiên cứu là do nhu cầu sử dụng và các đặc điểm nhân khẩu học (thu nhập của các hộ gia đình, số thành viên trong gia đình, nghề nghiệp và trình độ học vấn của đáp viên,...).

Bảng 2. Đặc điểm nhân khẩu học và nhu cầu sử dụng thiết bị điện gia dụng tại các địa điểm khảo sát

\begin{tabular}{|c|c|c|c|c|c|c|c|}
\hline \multirow[b]{2}{*}{$\begin{array}{l}\text { Địa điểm } \\
\text { nghiên cứu }\end{array}$} & \multirow{2}{*}{$\begin{array}{r}\text { Tổng số thiết } \\
\text { bị sử dụng } \\
\text { (chiếc) }\end{array}$} & \multirow{2}{*}{$\begin{array}{r}\text { Số nhân } \\
\text { khẩu } \\
\text { (người) }\end{array}$} & \multicolumn{5}{|c|}{ Số hộ dân phân theo thu nhập (triệu đồng/hộ) } \\
\hline & & & Dưới 2 & $\begin{array}{r}\text { Tù̀ } 2 \text { đến } \\
<5\end{array}$ & $\begin{array}{r}\text { Từ } 5 \text { dến } \\
<10\end{array}$ & $\begin{array}{r}\text { Từ } 10 \text { dến } \\
<15\end{array}$ & Trí \\
\hline$\overline{\mathrm{Ph}}$ & 403 & 129 & 0 & 0 & 5 & 5 & $\overline{20}$ \\
\hline Phu & 309 & 125 & 0 & 7 & 13 & 4 & \\
\hline Phường Long Tuyền & 311 & 124 & 1 & 9 & 14 & 4 & 2 \\
\hline Phường Tân Lộc & 374 & 129 & 0 & 6 & 12 & 10 & 2 \\
\hline
\end{tabular}

Kết quả khảo sát hiện trạng sử dụng của 120 hộ dân tại khu vực nghiên cứu cho thấy, hai loại thiết bị được sử dụng nhiều nhất là ĐTDĐ và quạt điện (429 chiếc), tiếp theo là ti vi (178 chiếc), tủ lạnh (121 chiếc), máy điều hòa (94 chiếc), máy giặt (86 chiếc) và máy vi tính là loại thiết bị ít được sử dụng nhất (60 chiếc). Tỷ lệ sử dụng của từng loại thiết bị trong mỗi hộ gia đình được trình bày trong Hình 1 , với tỷ lệ trung bình đối với mỗi loại thiết bị lần lượt là 3,$58 ; 1,48 ; 1,01 ; 0,78 ; 0,72$ và 0,50 chiếc/hộ. Trong 7 loại thiết bị được khảo sát, máy giặt, máy điều hòa và máy vi tính là các loại thiết bị có tỷ lệ sử dụng chênh lệch khá lớn giữa các địa điểm nghiên cứu. Trong đó, các hộ dân (được phỏng vấn) tại phường An Hòa có tỷ lệ sử dụng cao hơn so với các địa điểm còn lại. Tỷ lệ sử dụng khoảng 0,97 chiếc/hộ tại phường An Hoà đối với máy giặt, trong khi tỷ lệ được ghi nhận tại các phường còn lại chỉ dao động từ 0,60-0,67 chiếc/hộ. Một trong những nguyên nhân dẫn đến sự chênh lệch này có thể là do sự khác nhau về quỹ thời gian dành cho lao động sản xuất và thời gian làm việc nhà. Những người được phỏng vấn ở phường An Hòa thường dành nhiều thời gian cho các hoạt động sản xuất nên họ có nhu cầu sử dụng các thiết bị hỗ trợ làm việc nhà cao hơn. Điều này phù hợp với đặc điểm dân số của phường $A n$ Hòa với $100 \%$ dân số phân theo hoạt động phi nông nghiệp (Cục thống kê TP. Cần Thơ, 2016). Tương tự, máy điều hòa và máy vi tính cũng ít được sử dụng ở các hộ dân tại phường $\mathrm{Ba}$ Láng và Long Tuyền. Đây có thể được xem là loại thiết bị có phân khúc thị trường khá cao nên máy điều hòa chỉ được 59/120 hộ dân sử dụng, chủ yếu là những hộ dân có thu nhập khoảng 10-15 triệu đồng. Bên cạnh yếu tố về thu nhập, sự chênh lệch về trình độ học vấn cũng là một trong những nguyên nhân dẫn đến số lượng 
máy vi tính được sử dụng tại các địa điểm nghiên cứu khác nhau. Tỷ lệ máy vi tính giảm dần theo tỷ lệ đáp viên có trình độ học vấn trên trung học phổ thông với thứ tự lần lượt là phường An Hòa $(63,3 \%)$, phường Tân Lộc (50\%), phường $\mathrm{Ba}$ Láng $(43,3 \%)$ và phường Long Tuyền (10\%).



Hình 1. Tỷ lệ thiết bị điện tử gia dụng đang sử dụng trong mỗi hộ gia đình

Bên cạnh đó, nguyên nhân dẫn đến sự chênh lệch về số lượng của ĐTDĐ và ti vi là do thu nhập, nhu cầu sử dụng và sở thích mua sắm của các đáp viên. Tuy nhiên, ĐTDĐ là thiết bị cá nhân cần thiết trong thời đại công nghệ 4.0 nên hầu hết mỗi người trưởng thành đều sở hữu. Trong khi đó, tủ lạnh hầu như không có sự chênh lệch về số lượng sử dụng giữa các địa điểm nghiên cứu do đây là loại thiết bị phục vụ cho nhu cầu sinh hoạt chung của cả gia đình nên mỗi gia đình thường chỉ sở hữu một chiếc tủ lạnh.

Kết quả nghiên cứu cho thấy khi chất lượng cuộc sống của người dân được cải thiện, nhu cầu sử dụng các mặt hàng điện tử tiêu dùng ngày càng được nâng cao. Do đó, việc phát sinh lượng lớn rác thải điện tử gia dụng là hậu quả tất yếu. Tuy nhiên, đây là loại rác thải được liệt kê trong Danh mục chất thải nguy hại ban hành kèm Thông tư số 36/2015/TTBTNMT (Bộ Tài nguyên và Môi trường, 2015) với mã chất thải nguy hại $(\mathrm{CTNH})$ là 160113 và ngưỡng $\mathrm{CTNH}$ được ký hiệu là ** (là $\mathrm{CTNH}$ trong mọi trường hợp, không cần áp dụng ngưỡng $\mathrm{CTNH}$ mà xác định luôn là $\mathrm{CTNH})$. Tính chất nguy hại chính của các thiết bị, linh kiện điện tử này là có độc tính và độc tính sinh thái. Vì vậy, việc xử lý rác thải điện tử yêu cầu quy trình kỹ thuật và công nghệ cao.

\subsubsection{Hiện trạng phát sinh các thiết bị điện tủ gia dụng thái bỏ}

Sự phát triển nhanh của công nghệ đã làm đa dạng hóa mẫu mã, tính năng của các thiết bị điện tử, song về tuổi đời của sản phẩm lại có xu hướng giảm xuống (Nguyễn Thị Thanh Huyền, 2014). Trong các loại thiết bị được khảo sát, điện thoại di động là loại thiết bị có thời gian sử dụng ngắn nhất (dao động từ $3,8-4,8$ năm) và nơi có tuổi thọ thiết bị thấp nhất là phường An Hòa. Tuy nhiên, tuổi thọ của điện thoại tại khu vực nghiên cứu cao hơn so với mức 2 năm tại các tỉnh thành phía Bắc được đề cập trong nghiên cứu của Bùi Duy Cam và ctv. (2013). Đối với ti vi, có đến $104 / 120$ hộ dân chưa thải bỏ thiết bị này (chiếm 86,67\%). Trong số 14 hộ dân đã thải bỏ, tuối thọ của thiết bị này dao động từ $6-12$ năm và phường An Hòa vẫn là nơi có thời gian sử dụng ti vi ngắn nhất (chỉ từ $6-7$ năm). Trong khi đó, tuổi thọ của ti vi tại Philippines là 8 - 10 năm và tại Nhật Bản là 5 năm (Nguyễn Thị Thanh Huyền, 2014). Tủ lạnh là thiết bị có tuổi thọ khá dài, tại Nhật Bản là 10 năm và tại Philippines là từ $10-15$ năm (Nguyễn Thị Thanh Huyền, 2014). Còn tại các địa điểm nghiên cứu, có đến $90 \%$ hộ dân chưa thải bỏ loại thiết bị này, trong các hộ đã thải bỏ thì tuổi thọ của thiết bị này dao động từ $8-14$ năm. Tiếp theo, trong 85 hộ dân có sử dụng máy giặt, chỉ có duy nhất 1 hộ tại phường An Hòa đã thải bỏ thiết bị này và tuổi thọ của nó là 5 năm. Tuổi thọ của máy giặt trong nghiên cứu này thấp hơn rất nhiều so với tuồi thọ trung bình tại Philippines là 11 - 14 năm và tại Nhật Bản là 8 năm (Nguyễn Thị Thanh Huyền, 2014). Tương tự điện thoại di động, quạt điện là loại thiết bị được tất cả hộ dân sử dụng và có tuổi thọ trung bình từ 6,1 6,9 năm. Trong đó, phường An Hòa vẫn là nơi có 
thời gian sử dụng ngắn nhất (từ 4 - 7 năm). Đặc biệt, trong tất cả hộ dân được phỏng vấn, chưa có hộ nào thải bỏ máy điều hòa và máy vi tính.

Về nguyên nhân mua sắm thêm thiết bị mới, người dân tại phường $\mathrm{Ba}$ Láng cho rằng nguyên nhân chính là do thiết bị cũ bị hư hỏng (chiếm 73\%), còn lại là mua theo nhu cầu. Trong khi đó, nguyên

(a)

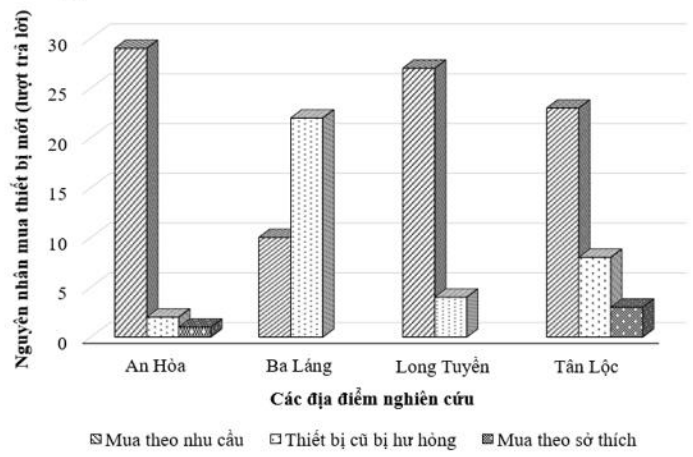

nhân chính tại 3 phường còn lại là mua theo nhu cầu với tỷ lệ lần lượt là $96,67 \%$; $90 \%$ và $76,67 \%$ cho phường An Hòa, phường Long Tuyền và phường Tân Lộc. Kết quả khảo sát này phù hợp với nghiên cứu của Đặng Thị Hường (2013), các sản phẩm điện, điện tử bị thải bỏ do bị hư hỏng hoặc do người sử dụng muốn thay thế chúng bằng những thiết bị hiện đại hơn.

(b)

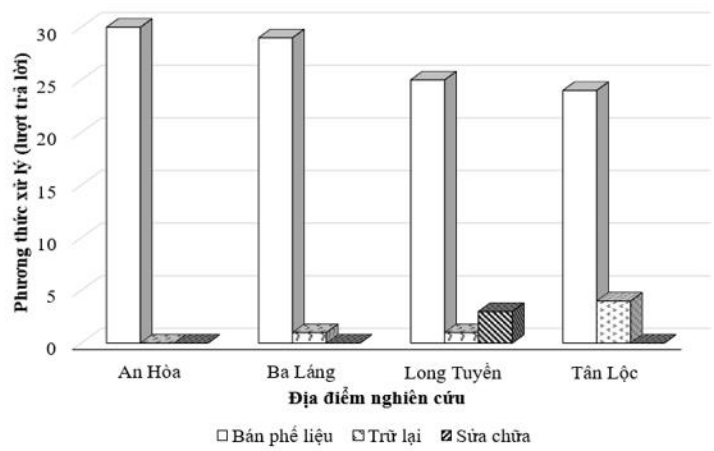

Hình 2. Biểu đồ thể hiện (a) nguyên nhân mua thêm thiết bị mới và (b) phương thức xử lý các thiết bị điện tử khi không sử dụng

Khi không còn sử dụng nữa, các thiết bị này được người dân xử lý bằng cách bán phế liệu, sửa chữa hoặc trữ lại. Trong đó, bán phế liệu là phương pháp được nhiều đáp viên áp dụng nhất vì có thể thu lại khoản phí nhỏ và giúp nhà cửa gọn gàng. Tỷ lệ hộ dân được phỏng vấn xử lý các thiết bị điện tử gia dụng bằng cách bán phế liệu lần lượt là $100 \%$ tại phường An Hòa; 96,67\% tại phường $\mathrm{Ba}$ Láng; $83,33 \%$ và $80 \%$ lần lượt cho phường Long Tuyền và Tân Lộc.
3.1.3. Dư đoán số luọng rác thải điện tử gia dụng phát sinh tại thành phố Cần Tho

Dựa trên số liệu được thu thập từ 120 hộ dân (507 người) tại các địa điểm khảo sát, nghiên cứu đã tính được tỷ lệ sử dụng của 7 loại thiết bị dao động từ $0,12-0,85$ chiếc/người. Cùng với dân số được ghi nhận trên địa bàn thành phố Cần Thơ là 1.236.000 người (Tổng cục Thống kê, 2020). Nghiên cứu tiến hành dự đoán tổng lượng rác thải điện tử gia dụng cho toàn thành phố Cần Thơ với giả định cho thị trường bão hòa, kêt quả ước tính được trình bày trong Bảng 3 .

Bảng 3. Số lượng các thiết bị điện tử gia dụng đang được sử dụng tại TPCT

\begin{tabular}{clrrr}
\hline STT & Loại thiết bị & $\begin{array}{r}\text { Số lượng sử dụng } \\
\text { (chiếc) }\end{array}$ & $\begin{array}{r}\text { Tỷ lệ thiết bị/người } \\
\text { (chiếc/người) }\end{array}$ & $\begin{array}{r}\text { Tổng số lượng thiết bị } \\
\text { phát sinh (chiếc) }\end{array}$ \\
\hline 1 & ĐTDĐ & 429 & 0,85 & 1.050 .600 \\
2 & Tivi & 178 & 0,35 & 432.600 \\
3 & Tủ lạnh & 121 & 0,24 & 296.640 \\
4 & Máy giặt & 86 & 0,17 & 210.120 \\
5 & Quạt điện & 429 & 0,85 & 1.050 .600 \\
6 & Máy điều hòa & 94 & 0,19 & 234.840 \\
7 & Máy vi tính & 60 & 0,12 & 148.320 \\
\hline
\end{tabular}

Kết quả ước tính cho thấy lượng rác thải điện tử gia dụng phát sinh trên toàn thành phố Cần Thơ là rất lớn. Trong đó, ĐTDĐ và quạt điện có số lượng cao vượt trội so với các thiết bị còn lại; điều này phù hợp với kết quả khảo sát về tuồi thọ trung bình được thải bỏ của thiết bị điện thoại di động. Tiếp đến là ti vi với lượng phát sinh cao gấp 1,5 lần so với tủ lạnh và lần lượt gấp 1,8 và 2,1 lần so với máy điều hòa và máy giặt. Do chỉ phục vụ nhu cầu của một bộ phận nhỏ đối tượng nên máy vi tính là loại thiết bị 
có tốc độ phát sinh thấp nhất. Với lượng phát thải được ước tính này, nếu không được thu gom và xử lý an toàn thì chất lượng môi trường có thể bị ô nhiễm nghiêm trọng do trong rác thải điện tử nói chung và rác thải điện tử gia dụng nói riêng có chứa nhiều hợp chất độc hại, chủ yếu là các kim loại nặng, các chất hữu cơ cao phân tử,... (Nguyễn Thu Hiền \& Trần Phương Thảo, 2019). Vì vậy, chính quyền địa phương cần có các chính sách quản lý, thu gom và xử lý phù hợp nhằm hạn chế các tác động phát sinh từ loại rác thải nguy hại này. Tuy nhiên, kết quả nghiên cứu chỉ dự đoán dựa trên số liệu trung bình ở cả thành thị và nông thôn; chính vì vậy cần có nhiều nghiên cứu hơn về việc phát thải rác thải điện tử gia dụng để đảm bảo tính chính xác và chắc chắn hơn.

\subsection{Công tác quản lý rác thải điện tử gia dụng tại khu vực nghiên cứu}

\subsubsection{Công tác thu gom và xủ lý rác thải điện tư gia dung}

Các chương trình phân loại và thu gom rác thải điện tử an toàn chưa được triển khai rộng rãi tại Việt Nam, loại rác thải này chủ yếu mới được tái chế sơ bộ bằng phương pháp thủ công (Nguyễn Thu Hiền \& Trần Phương Thảo, 2019; Nguyễn Thị Thoa và ctv., 2020). Tương tự, kết quả khảo sát tại khu vực nghiên cứu cho thấy $100 \%$ người dân được phỏng vấn cho biết rác thải điện tử trên địa bàn nghiên cứu không được chính quyền địa phương tổ chức thu gom chính thức, người dân chủ yếu bán cho những người thu mua phế liệu tự do hoặc mang đến các cơ sở điện cơ để sửa chữa.

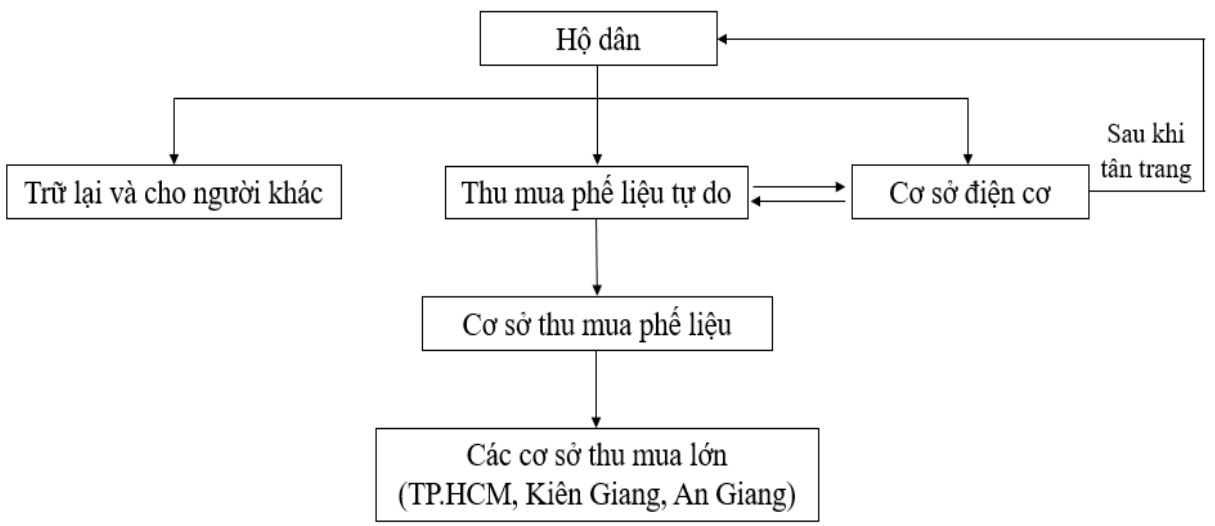

\section{Hình 3. Sơ đồ con đường phát sinh và thải bỏ các thiết bị điện tử}

Có thể thấy trong các loại hình hoạt động, người thu mua phế liệu tự do là một mắc xích quan trọng trong chuỗi thu gom và tái chế các thiết bị điện tử thải bỏ tại các địa điểm nghiên cứu. Những người được phỏng vấn cho biết hoạt động thu gom tận nhà không những mang lại nguồn thu từ việc bán các thiết bị không còn sử dụng mà còn đảm bảo mỹ quan và vệ sinh môi trường vì hạn chế được việc vứt bỏ chúng một cách bừa bãi. Đồng thời, hoạt động thu mua phế liệu tự do cũng giúp tái sử dụng những thiết bị còn khả dụng khi chúng được chuyển đến các cơ sở điện cơ để sửa chữa và tân trang. Tuy nhiên, đây cũng là nguyên nhân khiến một bộ phận nhỏ đáp viên không sẵn lòng tham gia vào các hoạt động thu gom và tái chế rác thải điện tử chính quy (nếu được tổ chức) do giá trị kinh tế nhận được từ các chương trình thu gom chính quy thấp hơn bán phế liệu. Kết quả phỏng vấn cho thây, những người thu mua phế liệu thường mua lại các thiết bị điện tử với giá 50.000-200.000 đồng đối với các thiết bị cỡ lớn như tủ lạnh, máy giặt. Trong khi đó, các chương trình thu gom và xử lý rác thải điện tử chính quy hoạt động trên sự tự nguyện của người dân và ưu tiên việc bảo vệ môi trường. Một ví dụ điển hình là chương trình Việt Nam Tái chế (chương trình thu hồi và xử lý rác thải điện tử an toàn) đã được triển khai tại Hà Nội và thành phố Hồ Chí Minh từ năm 2015. Theo chương trình, người dân sẽ mang các thiết bị điện tử không còn sử dụng đến các điểm thu gom hoặc sẽ được thu gom tận nhà định kỳ.

Bên cạnh người thu mua phế liệu tự do, các cơ sở sửa chữa điện cơ và cơ sở thu mua phế liệu cũng góp phần hạn chế số lượng thiết bị điện tử bị vứt bỏ bừa bãi ra môi trường và đóng góp vào kinh tế xã hội của địa phương. Tuy nhiên, số lượng thiết bị được thu gom còn hạn chế so với lượng phát sinh, trung bình người thu mua phế liệu tự do thu gom được từ 10-20 thiết bị/ngày. Đồng thời, việc tái chế các thiết bị điện tử chỉ được tiến hành tại các cơ sở điện cơ với số lượng thiết bị được sửa chữa dao động từ 7 đến 20 thiết bị/ngày, trong đó đã bao gồm các 
thiết bị khác (như nồi cơm điện, đầu đĩa, ampli). Tương tự với kết quả của các nghiên cứu trước, hoạt động phân tách, tháo dỡ thiêt bị điện tử diễn ra tại những cơ sở sửa chữa điện cơ và cơ sở thu mua phế liệu trong nghiên cứu này được thực hiện thủ công. Phương pháp phân tách thủ công này chỉ có thể thu hồi được các kim loại cơ bản, có giá trị thấp như đồng, sắt, nhôm,... Đồng thời, hoạt động này cũng tiềm ẩn nhiều nguy cơ cháy nổ và ô nhiễm môi trường như tích lũy kim loại nặng trong đất và nước (Someya et al., 2016; Hien et al., 2020). Đặc biệt là các rủi ro về sức khỏe khi tiếp xúc trực tiếp với rác thải điện tử trong quá trình tái chế (Tạ Thị Thảo và ctv., 2014; Perkins et al., 2014). Theo báo cáo của Nguyễn Thượng Hiền và ctv. (2015), cả nước chỉ có 26/83 cơ sở xử lý chất thải nguy hại được Tổng cục Môi trường cấp phép đầu tư công nghệ chuyên xử lý chất thải điện tử với công suất trung bình từ $0,3-5$ tấn/ngày. Trong đó, sản phẩm thu hồi từ công nghệ tái chế, thu hồi kim loại bằng phương pháp cơ lý có chất lượng thấp và cần được xử lý ở các công đoạn tiếp theo. Còn công nghệ tái chế, thu hồi kim loại bằng phương pháp hóa học và điện phân có thể thu hồi sản phẩm có chất lượng cao nhưng chỉ mới được áp dụng ở quy mô thử nghiệm, chưa được nhân rộng. Điều này cho thấy việc thúc đẩy thực hiện cơ chế thu hồi và xử lý các sản phẩm thải bỏ sau sử dụng không chỉ cần thiết cho riêng TPCT mà cần được triển khai trên phạm vi cả nước.

\subsubsection{Công tác tuyên truyền về tác hại của rác thải điện tử gia dụng}

Kết quả phỏng vấn ghi nhận ý kiến của $100 \%$ các cán bộ địa phương và người dân tại khu vực nghiên cứu về việc địa phương đã thực hiện nhiều chương trình, kế hoạch tuyên truyền, phổ biến pháp luật về bảo vệ môi trường đến người dân với nhiều hình thức phong phú, đa dạng như tổ chức các đoàn tuyên truyền đến từng hộ dân, phát tờ rơi, phát thanh,... Tuy nhiên, nội dung được tuyên truyền chủ yếu là về rác thải sinh hoạt như hướng dẫn phân loại rác thải, tuyên truyền về tác hại của việc xử lý rác không đúng cách (đốt tại nhà, vứt xuống kênh rạch,...) và vận động các hộ dân tham gia vào các tổ chức thu gom rác định kỳ (thông thường 1-2 ngày/lần). Còn các nôi dung về rác thải điện tử chưa được đề cập đến.

Tương tự như các hộ dân, đa số các cơ sở hoạt động liên quan đến thu hồi và xử lý các thiết bị điện tử thải bỏ cũng không được tuyên truyền về các tác hại của rác thải điện tử. Địa phương chỉ tổ chức tuyên truyền về phòng, chống cháy nổ và an toàn lao động cho các cơ sở thu mua phế liệu và sửa chữa thiết bị điện. Tai phường An Hòa, 2 cơ sở được tuyên truyền bằng hình thức phát tờ rơi và qua phương tiện truyền thông (phát thanh). Cơ sở tại phường Long Tuyền được tuyên truyền qua buổi họp dân và qua phương tiện truyền thông. Bên cạnh công tác tuyên truyền, địa phương còn cử cán bộ đến các cơ sở kiểm tra về vệ sinh môi trường, an toàn lao động và phòng chống cháy nổ với tần suất 1 lần/năm.

\subsection{Nhận thức cộng đồng về rác thải điện tử}

\subsubsection{Nhận thức về tác hại của rác thải điện tử}

Kết quả điều tra về nhận thức của các hộ dân tại các địa điểm nghiên cứu cho thấy trong tổng số 120 người được phỏng vấn, có 64 người $(53,33 \%)$ cho biết họ chưa từng nghe đến khái niệm "rác thải điện tử" và hoàn toàn không biết về các tác hại mà loại rác thải này mang lại. Tuy nhiên, khi được hỏi về các tác hại từ các thiết bị điện tử tiêu dùng trong gia đình, đa số người dân đưa ra các câu trả lời về các tác động đến sức khỏe và các nguy cơ cháy nổ xảy ra trong quá trình sử dụng. Có thể thấy, các đáp viên chỉ quan tâm đến các tác hại của các thiết bị điện tử trong giai đoạn sử dụng mà chưa biết đến các tác động sau khi chúng bị thải bỏ.

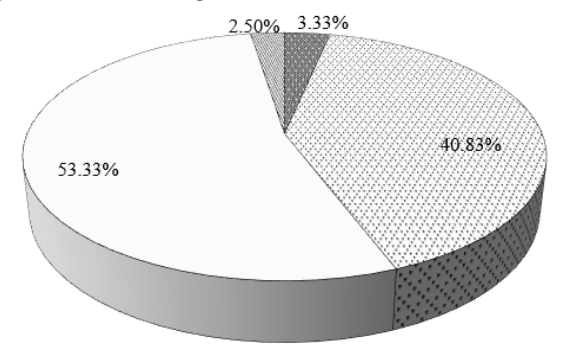

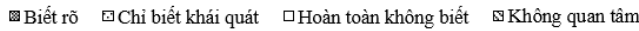

\section{Hình 4. Hiểu biết của 120 đáp viên về rác thải điện tử}

Bên cạnh 53,33\% người hoàn toàn không biết về rác thải điện tử, còn có $2,5 \%$ đáp viên cho biết họ không quan tâm đến những tác hại của chúng. Ngược lại, có 40,83\% người biết khái quát và 3,33\% người biết rõ về các tác hại của loại chất thải nguy hại này. Trong số đó, nhận thức của người dân tại phường An Hòa là khá cao, có đến 25/30 (83,33\%) người được hỏi có biết khái quát về rác thải điện tử thông qua các phương tiện truyền thông như tivi, sách, báo,...và nơi học tập. Tiếp đến là phường Tân Lộc, nơi có $10 \%$ người biết rõ và $43,33 \%$ biết khái quát về tác hại từ rác thải điện tử, trong số những người biết rõ các vấn đề liên quan đến rác thải điện tử có cán bộ làm việc trong UBND phường Tân Lộc. Đây là phường duy nhất có cán bộ địa phương hiểu 
biết rõ về khái niệm, đặc tính, cũng như các tác hại của rác thải điện tử đến sức khỏe và môi trường; còn cán bộ địa phương của các phường còn lại chỉ biết ở mức khái quát. Trong khi đó, các đáp viên tại phường Ba Láng và Long Tuyền có hiểu biết không
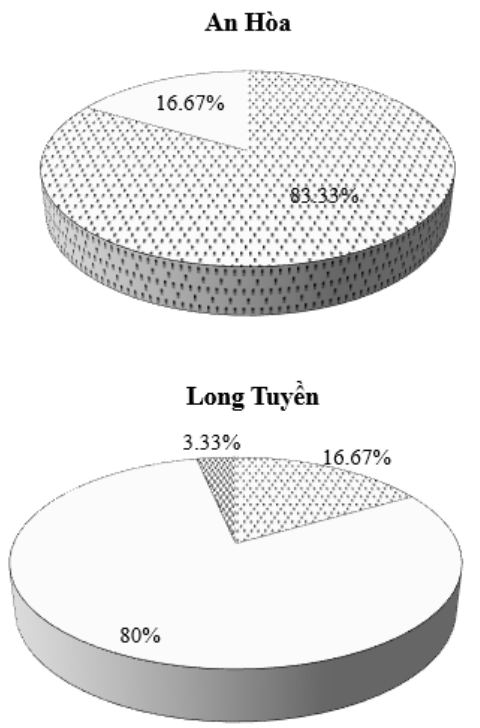

cao về rác thải điện tử, số người hoàn toàn không biết và không quan tâm đến rác thải điện tử tại các phường lần lượt là 23 người $(76,67 \%)$ và 25 người $(83,33 \%)$.
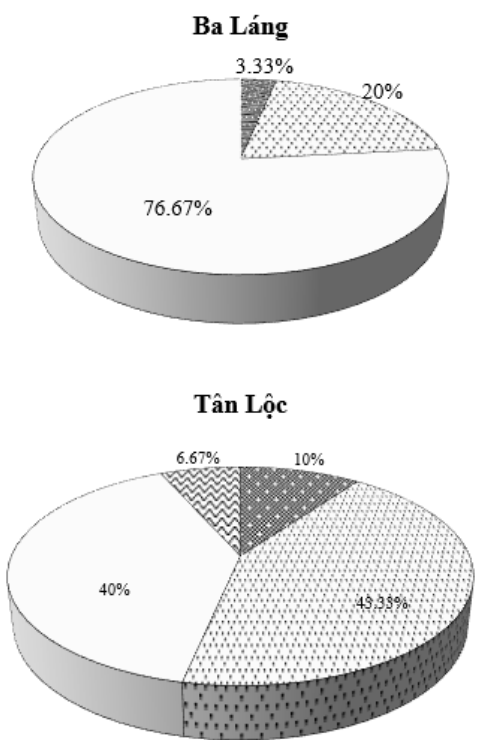

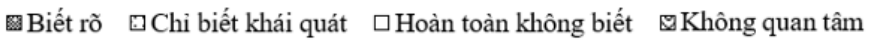

\section{Hình 5. Hiểu biết của các đáp viên tại mỗi địa điểm về rác thải điện tử}

Ngoài ra, kết quả khảo sát về nhận thức của những người tiếp xúc trực tiếp với rác thải điện tử gia dụng cho thấy họ cũng chỉ biết khái quát về tác hại của loại rác thải nguy hại này. Họ nêu được một số tác hại đến môi trường và sức khỏe con người như ô nhiễm kim loại nặng đến môi trường đất, nước; nguy cơ cháy nổ khá cao và đặc biệt đa số những người lao động này đều quan tâm đến vấn đề nhiễm độc chì. Tuy nhận thức được các tác hại của rác thải điện tử nhưng những người lao động này còn khá thờ ơ với an toàn sức khỏe của chính bản thân khi không sử dụng các dụng cụ bảo hộ trong quá trình thu gom, vận chuyển và xử lý. Chỉ có $3 / 16$ người (chiếm $18,75 \%$ ) có sử dụng bao tay trong quá trình thu gom và vận chuyển các thiết bị điện tử thải bỏ.

3.3.2. Kiến nghị về biện pháp hạn chế tác hại của rác thải điện tư gia dụng

Khảo sát về kiến nghị của người dân cho thấy $100 \%$ số người được hỏi đều muốn được tuyên truyền để nâng cao nhận thức về các tác hại của rác thải điện tử. Bên cạnh đó, có 10 lượt kiến nghị cần thành lập các điểm thu gom cố định và 9 lượt kiến nghị tổ chức các đội thu gom định kỳ. Về các điểm thu gom cố định, người dân cho rằng nên đặt tại UBND phường hoặc các hệ thống siêu thị điện máy với tần suất khoảng 2 lần/năm. Đối với đội thu gom định kỳ, hoạt động bằng cách đến nhà người dân thu gom và cũng được đề xuất với tần suất 2 lần/năm. Đặc biệt, có 3 người được phỏng vấn tại phường An Hòa thuộc quận Ninh Kiều kiến nghị nên xây dựng nhà máy xử lý rác thải điện tử để thu hồi hiệu quả các nguyên vật liệu và xử lý triệt để các chất thải nhằm mang lại lợi ích kinh tế cho địa phương, đảm bảo vệ sinh môi trường và sức khỏe cho cộng đồng.

Khi được hỏi về việc tham gia chương trình thu gom các thiết bị điện tử thải bỏ (không được hoàn trả bất kì khoản phí nào), hầu hết người dân sẵn lòng tham gia nếu được tuyên truyền và phổ biến chi tiết. Chỉ có $10 \%$ (12/120 người) không tham gia vì một số lý do như để bán phế liệu vì có thể thu lại một khoản tiền nhỏ hoặc để sử dụng cho mục đích khác (như cho người khác, trữ lại để làm vật kỷ niệm,...).

\section{KẾT LUẬN}

Số lượng thiết bị điện tử gia dụng sử dụng bình quân hộ gia đình đã được ghi nhận là điện thoại di động và quạt điện $>$ ti vi $>$ tủ lạnh $>$ máy điều hòa $>$ máy giặt > máy vi tính với tỷ lệ trung bình lần lượt là 3,$58 ; 1,48 ; 1,01 ; 0,78 ; 0,72$ và 0,50 chiếc/hộ. Trong đó, điện thoại di động là loại thiết bị có tuồi 
thọ thấp nhất (3,8 - 4,8 năm), tiếp đến là quạt điện và ti vi, các thiết bị còn lại hầu như chưa bị thải bỏ. Khu vực nghiên cứu chưa triển khai các chương trình thu gom và xử lý rác thải điện tử gia dụng an toàn, hầu hết các thiết bị điện tử thải bỏ được người dân bán phế liệu hoặc sửa chữa để dùng lại. Hoạt động phân tách kim loại tại các cơ sở phế liệu và điện cơ tiềm ẩn nhiều nguy cơ gây cháy nổ và ô nhiễm môi trường. Ngoài ra, công tác tuyên truyền về rác thải điện tử cũng chưa được thực hiện tại các địa điểm nghiên cứu. Bên cạnh đó, nhận thức của các đáp viên về rác thải điện tử là khá thấp. Cần tiếp tục mở rộng quy mô nghiên cứu tại các huyện, xã của TPCT để có số liệu so sánh giữa khu vực thành thị và nông thôn. Đồng thời, cần điều tra xa hơn về đường đi của rác thải điện tử khi được vận chuyển đến các cơ sở thu mua phế liệu lớn trên địa bàn thành phố.

\section{TÀI LIỆ THAM KHẢO}

Bộ Tài nguyên và Môi trường. (2015). Thông tư số 36/2015/TT-BTNMT về Quản lý chất thải nguy hại. https://thuvienphapluat.vn/van-ban/Tainguyen-Moi-truong/Thong-tu-36-2015-TTBTNMT-quan-ly-chat-thai-nguy-hai282119.aspx

Bùi Duy Cam, Đỗ Quang Trung, Nghiêm Xuân Thung, Tạ Thị Thảo, Chu Xuân Quang, Trịnh Xuân Đại, Đoàn Văn Hường \& Nguyễn Mạnh Hà. (2013). Khảo sát, đánh giá thực trạng và xây dựng mô hình về quản lý, công nghệ tái chế một số thiết bị điện tử thải bỏ (tivi, máy tính, điện thoại, tủ lạnh) thí điểm cho vùng kinh tế trọng điểm phía Bắc trong giai đoạn 2010-2020. Đề tài nghiên cứu khoa học, Đại học quốc gia Hà Nội. 324 trang.

Cục Thống kê thành phố Cần Thơ. (2016). Niên giám thống kê quận Ninh Kiều năm 2015.

Đặng Thị Hường (2013). Nghiên cúu đánh giá tiềm năng tái chế chất thải điện tư và thu hồi kim loại có giá trị tù bản mạch điện tử thải bỏ (Luận văn Thạc sĩ Khoa học). Đại học Quốc gia Hà Nội.

Hai, H. T., Hung, H. V., \& Quang, N. D. (2017). An overview of electronic waste recycling in Vietnam. Journal of Material Cycles and Waste Management, 19(1), 536-544.

Hien, N.T.T., Liang, L., Diep, N.B., Hai, D.N., \& Watchalayann, P. (2020). Environmental Pollution of Heavy Metals in a Vietnamese Informal E-waste Processing Village. Applied Environmental Research, 42(1), 71-84.
Nguyễn Thị Thanh Huyền. (2014). Nghiên cứu áp dụng các phương pháp tính toán xác định lượng thải của chất thải điện tử gia dụng để dự báo lượng thải của một số thiết bị gia dụng điển hình ở Việt Nam đến năm 2025. Viện Khoa học và Công nghệ Môi trường (INEST). Đại học Bách Khoa Hà Nội. 56 trang.

Nguyễn Thị Thoa, Bùi Thị Lư \& Trần Quang Hải. (2020). Nghiên cứu thu hồi kim loại đồng từ bản mạch điện tử phế thải theo hướng an toàn với môi trường. Tap chí Khoa học và Công nghệ, 56(4), 122-124.

Nguyễn Thu Hiền \& Trần Phương Thảo. (2019). Hoạt động tái chế chất thải điện tử ở Việt Nam và một số khuyến nghị. Tạp chí Khoa hoc Công nghệ truờng Đại học Công nghiệp Hà Nội, 53, 101-106.

Ohajinwa, C.M., Bodegom, P.M.V., Vijver, M.G. \& Peijnenburg, W.J.G.M. (2017). Health Risks Awareness of Electronic Waste Workers in the Informal Sector in Nigeria. International Journal of Environmental Research and Public Health, 14(8).

Olowofoyeku, A.E. (2020). Knowledge, Attitude and Practices of E-Waste Workers in Owode-Onirin Scrap Market, Kosofe Local Government Area, Langos State, Nigeria. J. Appl. Sci. Environ. Manage., 24(8), 1315-1320.

Perkins, D.N., Drisse, M.B., Nxele, T. \& Sly, P.D. (2014). E-Waste: A Global Hazard. Annals of Global Health, 80(4), 286-295.

Someya, M., Suzuki, G., Lonas, A.C., Nguyen, M.T., Xu, F., Matsukami, H., Covaci, A., Tuyen, L.H., Hung, P.V., Takahashi, S., Tanabe, S. \& Takigami, H. (2016). Occurrence of emerging flame retardants from e-waste recycling activities in the northern part of Vietnam. Emerging Contaminants, 2(2), 58-65.

Tạ Thị Thảo, Nguyễn Mạnh Hà, Bùi Duy Cam \& Đỗ Quang Trung. (2014). Đánh giá mức độ ô nhiễm kim loại nặng trong nước ngầm và tích lũy kim loại nặng trong tóc và móng tay của cư dân tại khu vực thu gom và tái chế chất thải điện tử. Tạp chí phân tích Hóa, Lý và Sinh học, 20(1), 111-119.

Tổng cục Thống kê. (2020). Niên giám Thống kê Việt Nam năm 2019.

Zeng, X., Duan, H., Wang, F., \& Li, J. (2017). Examining environmental management of ewaste: China's experience and lessons. Renewable and Sustainable Energy Reviews, 72, 1076-1082. 